\title{
Effect of Hydrogen on Creep of SUS304
}

\author{
Daisuke Takazaki ${ }^{1 *}$, Masanobu Kubota ${ }^{2}$ \\ ${ }^{1}$ Graduate School of Mechanical Engineering, Kyushu University, 744 Motooka, Nishi-ku, Fukuoka, Japan \\ ${ }^{2}$ International Institute for Carbon-Neutral Energy Research (WPI-I2CNER), Kyushu University, 744 Motooka, Nishi-ku, Fukuoka, \\ Japan \\ *takazaki12@kyudai.jp
}

Introduction. The objective of this study is to clarify the effect of high-temperature hydrogen on the creep properties for advanced hydrogen energy technologies such as SOFC, SOEC, RFC and a hydrogen gas turbine.

Experimental procedure. We first developed a new testing machine that enables material testing in hightemperature hydrogen as shown in Fig . 1. The SSRT (Slow Strain Rate Testing) and creep test were then conducted in $\mathrm{Ar}$ and $\mathrm{H}_{2}$ under a gas pressure of 0.12 MPa absolute presure in accordance with ASTM G129 and JIS Z2271, respectively. The shape of the specimen is shown in Fig. 2. The test material was JIS SUS304 austenitic stainless steel. The strain rate for the SSRT was $10^{-5} 1 / \mathrm{s}$. The creep test was carried out at $600{ }^{\circ} \mathrm{C}$ in Ar and $\mathrm{H}_{2}$.

Results. Figure 3 shows the results of the SSRT. A significant ductility loss due to the hydrogen occurred at $25{ }^{\circ} \mathrm{C}$. On the other hand, no ductility loss occurred at $100{ }^{\circ} \mathrm{C}$ and higher temperatures. The possible reasons are an interaction between the hydrogen and deformation and microstructure changes. Dislocations, which act as hydrogen trapping sites at room temperature, do not work as hydrogen trapping sites at high temperature ${ }^{(1)}$. In addition, strain-induced martensite transformation, which enhances the effect of hydrogen at room temperature, is suppressed at high temperature ${ }^{(2)}$. As an important result obtained from this experiment, the work hardening rate in $\mathrm{H}_{2}$ at $600{ }^{\circ} \mathrm{C}$ decreased compared for that in $\mathrm{Ar}$ at $600{ }^{\circ} \mathrm{C}$. Considering no interaction between the dislocations and hydrogen, different mechanisms that affect the deformation in hydrogen are expected.

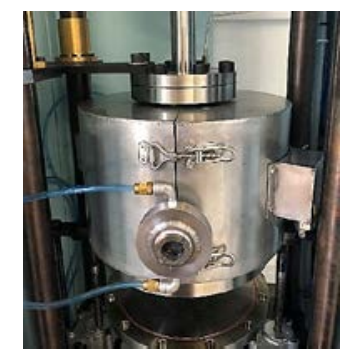

Fig. 1 Testing machine for SSRT and creep in $\mathrm{Ar}$ and $\mathrm{H}_{2}$ at $600{ }^{\circ} \mathrm{C}$

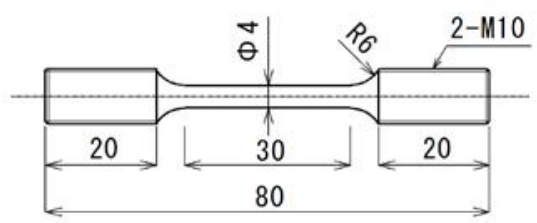

Fig. 2 SSRT and creep specimen
Figure 4 shows the creep rupture time curves in $\mathrm{Ar}$ and $\mathrm{H}_{2}$. The creep life was significantly reduceed in hydrogen. Yokogawa reported that hydrogen reduced the creep life ${ }^{(3)}$. This study reproduced the trend of their experiment. The morphology of the fracture surface is also shown in Fig . 4. In Ar, dimple and intergranular fracture surfaces were observed at $\sigma=310 \mathrm{MPa}$. Most of the fracture surface was covered by intergranular cracking when $\sigma=270 \mathrm{MPa}$. In $\mathrm{H}_{2}$, the major fracture surface was dimple at $\sigma=310 \mathrm{MPa}$, and dimple and intergranular fracture surfaces at $\sigma=270 \mathrm{MPa}$. The change in the fracture surface and the change in the slope of the creep curve suggested multiple reasons for hydrogen affecting the creep life.

\section{References.}

(1) Takai, K., Trans Jpn Soc Mech Eng, (2004), 10271035.

(2) Koide, K., et al., Zairyo-to-kankyo, (2014), 523-527.

(3) Yokogawa, K., Bulletin of the Japan Institute of Metals, (1982), 783-791

Acknowledgement. This study was supported by the Research Fellow of Japan Society for Promotion of Science (JSPS) for Young Scientists and JSPS KAKENHI Grant Numbers 16H04237and 18J22540.

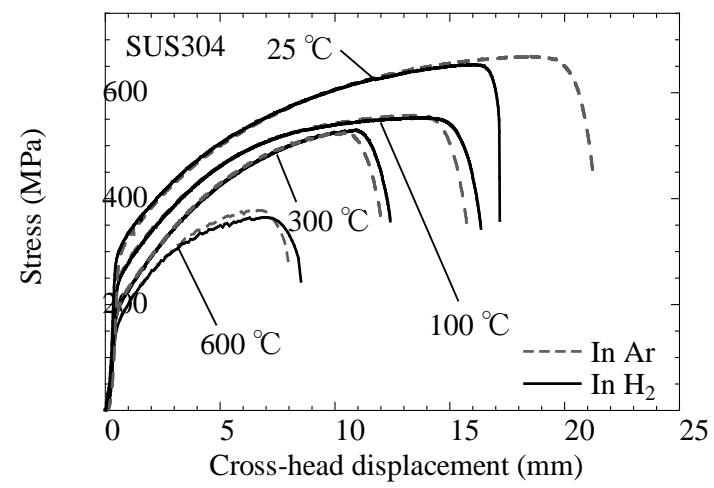

Fig. 3 Effect of temperature on SSRT of SUS304 in $\mathrm{H}_{2}$

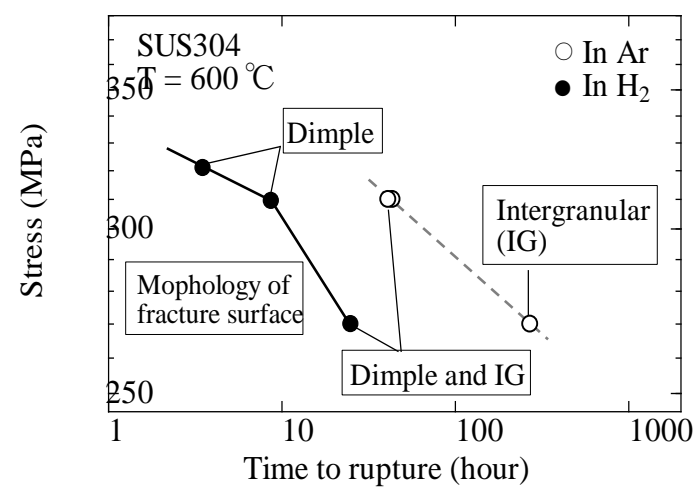

Fig. 4 Reduction of creep life of SUS304 by $\mathrm{H}_{2}$ 